\title{
Litopenaeus vannamei stylicins are constitutively produced by hemocytes and intestinal cells and are differentially modulated upon infections
}

\author{
Farias Natanael Dantas ${ }^{1}$, Falchetti Marcelo ${ }^{1}$, Matos Gabriel Machado ${ }^{1}$, Schmitt Paulina ${ }^{2}$, \\ Barreto Cairé ${ }^{1}$, Argenta Nicolas ${ }^{1}$, Rolland Jean-Luc ${ }^{3}$, Bachère Evelyne ${ }^{3}$, Perazzolo Luciane Maria ${ }^{1}$, \\ Rosa Rafael Diego ${ }^{1,}$
}

${ }^{1}$ Laboratory of Immunology Applied to Aquaculture, Department of Cell Biology, Embryology and Genetics, Federal University of Santa Catarina, 88040-900, Florianópolis, SC, Brazil

${ }^{2}$ Laboratorio de Genética e Inmunología Molecular, Instituto de Biología, Facultad de Ciencias,

Pontificia Universidad Católica de Valparaíso, 2373223, Valparaíso, Chile

${ }^{3}$ Interactions Hôtes-Pathogènes-Environnements, Université de Montpellier, CNRS, Ifremer, Université de Perpignan Via Domitia, 34090, Montpellier Cedex 5, France

*Corresponding author : Rafael Diego Rosa, email address : rafael.d.rosa@ufsc.br

\begin{abstract}
:
Stylicins are anionic antimicrobial host defense peptides (AAMPs) composed of a proline-rich N-terminal region and a $\mathrm{C}$-terminal portion containing 13 conserved cysteine residues. Here, we have increased our knowledge about these unexplored crustacean AAMPs by the characterization of novel stylicin members in the most cultivated penaeid shrimp, Litopenaeus vannamei. We showed that the $L$. vannamei stylicin family is composed of two members (Lvan-Stylicin1 and Lvan-Stylicin2) encoded by different loci which vary in gene copy number. Unlike the other three gene-encoded antimicrobial peptide families from penaeid shrimp, the expression of Lvan-Stylicins is not restricted to hemocytes. Indeed, they are also produced by the columnar epithelial cells lining the midgut and its anterior caecum. Interestingly, Lvan-Stylicins are simultaneously transcribed at different transcriptional levels in a single shrimp and are differentially modulated in hemocytes after infections. While the expression of both genes showed to be responsive to damage-associated molecular patterns, only Lvan-Stylicin2 was induced after a Vibrio infection. Besides, Lvan-Stylicins also showed a distinct pattern of gene expression in the three portions of the midgut (anterior, middle and posterior) and during shrimp development. We provide here the first evidence of the diversity of the stylicin antimicrobial peptide family in terms of sequence and gene expression distribution and regulation.
\end{abstract}




\section{Highlights}

- Stylicins from L. vannamei are composed of two members, Lvan-Stylicin1 and -2. L Lan-Stylicins are encoded by separate genes and transcribed at different levels. Lvan-Stylicins are expressed in hemocytes and in midgut epithelial cells. Expression of Lvan-Stylicins is differentially modulated in response to infections.

Keywords : Crustacean, Penaeid shrimp, Invertebrate immunity, Antimicrobial peptide, Host defense peptide, Molecular diversity 


\section{Introduction}

Antimicrobial host defense peptides (AMPs) are important components of the

47 innate immune system of both vertebrates and invertebrates. They are usually described as gene-encoded peptides (less than $10 \mathrm{kDa}$ ) with cationic and amphipathic properties which selectively target the negatively charged membranes of microbes [1]. In addition to those classical cationic antimicrobial peptides (also known as CAMPs), the current classification of AMPs also includes polypeptides/proteins larger than $10 \mathrm{kDa}$, AMPs generated by the processing of precursor molecules and anionic peptides [2]. Anionic antimicrobial peptides (AAMPs) comprise a non-phylogenetic group of either geneencoded or non-ribosomally synthesized molecules with a high proportion of anionic amino acid residues (aspartate and glutamate). AAMPs are widely distributed in living organisms and play an important role in host defense against bacteria, fungi and viruses [3]. Like their cationic counterparts, AAMPs are multifunctional molecules engaged in different biological and immunological processes beyond antimicrobial functions [3].

Shrimp farming is an important economic activity for many developing countries

60 in Asia and Latin America, which has been repeatedly threatened by infections caused

61 by viruses and pathogenic bacteria from the genus Vibrio. Consequently, infectious disease outbreaks are clearly a major concern in aquaculture that has encouraged extensive research efforts. The scientific findings in the last decade have provided

64 valuable information on the role of AMPs in shrimp defenses. More than natural antibiotics, shrimp AMPs are also involved in the control of the natural microbiota,

66 wound healing, bacterial clearance and other immunomodulatory functions [4]. To date,

67 four gene-encoded AMP families have been identified in the hemocytes of penaeid shrimp: penaeidins, crustins, anti-lipopolysaccharide factors (ALFs) and stylicins [4,5]. 
Stylicins were initially identified as transcripts associated to shrimp survival to

70 pathogenic Vibrio infections [6]. Characterization of stylicins revealed that they are

71 anionic peptides of $8.9 \mathrm{kDa}$ composed of an N-terminal proline-rich region followed by

72 a C-terminal region containing 13 cysteine residues [7]. In Litopenaeus stylirostris

73 shrimp, stylicins form a diverse AAMP family composed of two members, named Lsty-

74 Stylicin1 and Lsty-Stylicin2. Although the antimicrobial activity of the recombinant

75 rLsty-Stylicin1 has been shown to be restricted to filamentous fungi, the rLsty-Stylicin1

76 displayed a strong lipopolysaccharide (LPS)-binding activity and the ability to

77 agglutinate Gram-negative bacteria [7]. In the kuruma prawn Marsupenaeus japonicus,

78 the gene expression of its single stylicin (Mjap-Stylicin) showed to be modulated in

79 gills and hepatopancreas in response to the White spot syndrome virus (WSSV) [8].

80 Curiously, apart from these two reports $[7,8]$, no other stylicin members have been 81 characterized thus far.

82 In order to fill this research gap, novel members of the stylicin AMP family were 83 identified and characterized in the most important cultured penaeid species, Litopenaeus 84 vannamei (Lvan-Stylicin1 and Lvan-Stylicin2). We showed that Lvan-Stylicins (also 85 known as Vibrio penaeicida-induced cysteine and proline-rich peptides or $L v$ VICPs [9]) 86 are highly anionic peptides encoded by two distinct genomic loci that follow different 87 patterns of gene regulation during shrimp development and after microbial infections. 88 Interestingly, while both genes responded to danger/damage-associated molecular 89 patterns (shrimp muscle tissues), only Lvan-Stylicin2 showed to be up-regulated in 90 circulating hemocytes in response to a Vibrio infection. Moreover, by combining 91 immunohistochemistry and whole-mount immunofluorescence assays, we showed that 92 Lvan-Stylicins are also constitutively produced by the midgut columnar epithelial cells. 
93 To our knowledge, this is the first evidence for the expression of a shrimp gene-encoded

94 AMP in other tissues than the immune cells from the hemolymph.

95

\section{Materials and Methods}

\subsection{Animals, immune challenge and tissue collection}

Juvenile Pacific white shrimp (Litopenaeus vannamei) $(10 \pm 2 \mathrm{~g})$ were obtained

from the Laboratory of Marine Shrimp of the Federal University of Santa Catarina

100 (Southern Brazil). After an acclimation period of seven days, animals $(n=5)$ were

101 stimulated by the injection of $5 \times 10^{7}$ colony-forming units (CFU)/animal of heat killed

$102\left(70^{\circ} \mathrm{C}\right.$ for $\left.20 \mathrm{~min}\right)$ Vibrio harveyi ATCC 14126 in $100 \mu \mathrm{L}$ sterile seawater (SSW).

103 Naïve (unchallenged) animals $(\mathrm{n}=5)$ were used as control. At $48 \mathrm{~h}$ post-stimulation, 104 hemolymph was withdrawn into modified Alsever solution (MAS: $27 \mathrm{mM}$ sodium

105 citrate, $336 \mathrm{mM} \mathrm{NaCl}, 115 \mathrm{mM}$ glucose, $9 \mathrm{mM}$ EDTA, $\mathrm{pH}$ 7.0) and hemocytes were

106 separated from plasma by centrifugation $\left(800 \times g\right.$ for $10 \mathrm{~min}$ at $\left.4^{\circ} \mathrm{C}\right)$. Shrimp were

107 subsequently anesthetized (ice bath for $10 \mathrm{~min}$ ) and sacrificed for the collection of the

108 following tissues: gills, muscle, nerve cord, hepatopancreas, foregut, midgut and 109 hindgut. Tissue samples were washed in Tris-saline solution (10 mM Tris, $330 \mathrm{mM}$

$110 \mathrm{NaCl}, \mathrm{pH}$ 7.4), homogenized in TRIzol reagent (Thermo Scientific) and immediately

111 processed for total RNA isolation and tissue distribution analysis. Pleopods from naïve

112 shrimp were collected and processed for genomic DNA (gDNA) extraction.

114 2.2. Experimental infections

115 Two unrelated shrimp pathogens were chosen for experimental infections, the

116 Gram-negative Vibrio harveyi and the White spot syndrome virus (WSSV). For the 
117 bacterial infection, $6 \times 10^{7} \mathrm{CFU} /$ animal of live V. harveyi ATCC 14126 in $100 \mu \mathrm{L}$ SSW

118 (median lethal dose within 2 days, LD50/2) or $100 \mu \mathrm{L}$ SSW (injury control) were

119 injected. For the viral infection, shrimp were injected with $100 \mu \mathrm{L}$ of a WSSV inoculum

120 containing $3 \times 10^{2}$ viral particles (median lethal dose within 15 days, LD50/15). The

121 WSSV inoculum was prepared from muscle tissues of WSSV-infected shrimp as

122 previously described [10]. Control animals for the viral infection were injected with 100

$123 \mu \mathrm{L}$ of a muscle tissue homogenate prepared from WSSV-free shrimp. At $48 \mathrm{~h}$ post-

124 infections, circulating hemocytes and midguts were collected, pooled (3 pools of 5

125 animals per condition) and processed for total RNA extraction and quantitative PCR

126 analysis of gene expression. Unchallenged animals (naïve shrimp at time $0 \mathrm{~h}$ ) were used

127 as control for all experiments.

128 In a second experiment, individual shrimp $(n=3)$ were challenged by the oral

129 administration of $7.5 \times 10^{5}$ CFU/animal of live $V$. harveyi ATCC 14126 in $50 \mu \mathrm{L}$ SSW.

130 Shrimp $(n=3)$ that received SSW served as controls. The bacterial per os challenge was

131 performed as previously described [11]. No mortalities were recorded during the course

132 of the experiment. At $21 \mathrm{~h}$ post-challenge, midguts from both Vibrio-challenged and

133 unchallenged shrimp were collected and flushed with cold Tris-saline solution and then

134 cut into three equal portions (anterior, middle and posterior). Each individual sample

135 was homogenized in TRIzol reagent (Thermo Scientific) and processed for total RNA

136 extraction and quantitative PCR analysis of gene expression.

137

138 2.3. Genomic DNA and total RNA extraction and cDNA synthesis

139 For gDNA extraction, individual pleopods were homogenized and incubated at

$14055^{\circ} \mathrm{C}$ for $1 \mathrm{~h}$ in $500 \mu \mathrm{L}$ of lysis buffer $(100 \mathrm{mM}$ Tris- $\mathrm{HCl} \mathrm{pH} 8.5,100 \mathrm{mM} \mathrm{NaCl}, 50$ 
$141 \mathrm{mM}$ EDTA $\mathrm{pH} 8.0,1 \%$ SDS, $0.25 \mu \mathrm{g} / \mu \mathrm{L}$ proteinase $\mathrm{K})$. After addition of $3 \mathrm{M}$

142 potassium acetate $(1: 2 ; \mathrm{v}: \mathrm{v})$, samples were incubated at $4{ }^{\circ} \mathrm{C}$ for $30 \mathrm{~min}$ and centrifuged

143 at $14,000 \times g$ for $10 \mathrm{~min}$. Following precipitation with isopropanol, gDNA samples were

144 washed in $70 \%$ ethanol and treated with $50 \mu \mathrm{g} / \mathrm{mL}$ RNase A (Fermentas) at $37^{\circ} \mathrm{C}$ for 30

145 min. Quantification and quality of gDNA samples were assessed by spectrophotometry

146 and $0.8 \%$ agarose gel electrophoresis, respectively.

147 Total RNA was extracted using TRIzol reagent (Thermo Scientific) according to

148 the manufacturer's instructions. RNA samples were treated with DNase I (Thermo

149 Scientific) at $37^{\circ} \mathrm{C}$ for $15 \mathrm{~min}$ and precipitated with $0.3 \mathrm{M}$ sodium acetate (pH 5.2) and

150 isopropanol (1:1; v:v). RNA amount and quality were assessed by spectrophotometric

151 analysis and the integrity of total RNA was analyzed by $0.8 \%$ agarose gel

152 electrophoresis. Following heat denaturation $\left(70^{\circ} \mathrm{C}\right.$ for $\left.5 \mathrm{~min}\right)$, reverse transcription was

153 performed using $1 \mu \mathrm{g}$ of purified total RNA with $50 \mathrm{ng} / \mu \mathrm{L}$ oligo $(\mathrm{dT})_{12-18}$ in a $20-\mu \mathrm{L}$

154 reaction volume containing the RevertAid Reverse Transcriptase (Thermo Scientific),

155 according to the manufacturer's instructions.

156

157 2.4. Molecular cloning

158 PCR amplifications for molecular cloning were conducted using primers based on

159 the nucleotide sequence of two stylicin homologues (contigs: DN31608_c0_g1_i1 and

160 DN31608_c0_g1_i2) identified in midgut transcriptomes of L. vannamei (unpublished

161 data). PCR reactions were carried out in a $15-\mu \mathrm{L}$ reaction volume containing $50-100 \mathrm{ng}$

162 of gDNA, $2 \mathrm{mM} \mathrm{MgCl} 2,0.4 \mathrm{mM}$ dNTP Mix, $0.4 \mu \mathrm{M}$ of each primer (Table 1) and $1 \mathrm{U}$

163 Taq DNA Polymerase (Sinapse). PCR conditions were as follows: 1 cycle of

164 denaturation at $95^{\circ} \mathrm{C}$ for 10 min followed by 35 cycles of $95^{\circ} \mathrm{C}$ for $45 \mathrm{~s}, 55^{\circ} \mathrm{C}$ for $45 \mathrm{~s}$ 
165 and $72^{\circ} \mathrm{C}$ for $2 \mathrm{~min}$, and a final extension step of $72^{\circ} \mathrm{C}$ for $10 \mathrm{~min}$. The amplification

166 products were analyzed by electrophoresis (1.5\% agarose gel) and cloned into a

167 pCR2.1-TOPO vector (Thermo Scientific). The positive clones were identified by

168 colony PCR and plasmid sequencing.

169

$170 \quad$ 2.5. Sequence data analysis and phylogeny

171 Stylicin sequences from the penaeid species L. vannamei (contigs:

172 DN31608_c0_g1_i1 and DN31608_c0_g1_i2), L. stylirostris (Lsty-Stylicin1:

173 EU177435; Lsty-Stylicin2: EU177437) and M. japonicus (Mjap-Stylicin: KR063277)

174 were used for the search of homologous sequences in the following publicly accessible

175 databases: Expressed Sequence Tags (EST), Transcriptome Shotgun Assembly (TSA)

176 and Whole-Genome Shotgun Contigs (WGS). Only full-length coding sequences were

177 included. Homology searches were performed using tBLASTX at the NCBI web servers

178 (http://www.ncbi.nlm.nih.gov/BLAST). All nucleotide sequences were manually

179 inspected and translated using the ExPASy Translate Tool

180 (http://web.expasy.org/translate/). Prediction of signal peptide was performed with the

181 SignalP 4.1 program (http://www.cbs.dtu.dk/services/SignalP/) and the theoretical

182 isoelectric point $(\mathrm{p} I)$ and molecular weight (MW) of the mature peptides were predicted

183 using the ExPASy ProtParam Tool (http://web.expasy.org/protparam/). Phylogenetic

184 analysis based on both nucleotide and predicted amino acid sequences were conducted

185 in MEGA X [12] using the Maximum Likelihood method. Bootstrap sampling was

186 reiterated 1,000 times using a $50 \%$ bootstrap cutoff.

187

188 2.6. Semiquantitative RT-PCR analysis 
189 The extraction of total RNA and cDNA synthesis were performed using the

190 method described above. PCR reactions were carried out in a $15-\mu \mathrm{L}$ reaction volume

191 containing $1 \mu \mathrm{L}$ of cDNA, $2 \mathrm{mM} \mathrm{MgCl} 2,0.4 \mathrm{mM}$ dNTP Mix, $0.4 \mu \mathrm{M}$ of each primer

192 (Table 1) and 1 U Taq DNA Polymerase (Sinapse). PCR conditions were as follows: 1

193 cycle of denaturation at $95^{\circ} \mathrm{C}$ for $5 \mathrm{~min}$ followed by 30 cycles of $95^{\circ} \mathrm{C}$ for $30 \mathrm{~s}, 57^{\circ} \mathrm{C}$ for

$19430 \mathrm{~s}$ and $72^{\circ} \mathrm{C}$ for $30 \mathrm{~s}$, and a final extension step of $72^{\circ} \mathrm{C}$ for $10 \mathrm{~min}$. PCR products

195 were analyzed by electrophoresis (1.5\% agarose gel) and stained by ethidium bromide.

196 The expression of the $L v$ Actin gene (PCR conditions: 40 cycles of $95^{\circ} \mathrm{C}$ for $45 \mathrm{~s}, 50^{\circ} \mathrm{C}$

197 for $45 \mathrm{~s}$ and $72^{\circ} \mathrm{C}$ for $1 \mathrm{~min}$ ) was used as endogenous control to normalize the RT-PCR

198 data for comparison.

199

\subsection{Immunodetection of stylicins in shrimp tissues}

Whole juvenile shrimp $(n=3)$ were fixed in Davidson's fixative solution $(22 \%$

202 formalin, $31.5 \%$ ethanol and $11.5 \%$ glacial acetic acid) for $24 \mathrm{~h}$ at room temperature,

203 embedded in paraffin and cut into $5 \mu \mathrm{m}$ thick sections. Histological sections of shrimp

204 tissues were deparaffinized and hydrated through xylene-ethanol-water series, and 205 washed in Tris-buffered saline (TBS: $50 \mathrm{mM}$ Tris-HCl, $200 \mathrm{mM} \mathrm{NaCl}, \mathrm{pH}$ 7.2). Then, 206 sections were permeabilized (1×TBS, $0.1 \%$ Triton $\mathrm{X}-100)$ for $30 \mathrm{~min}$ and blocked in 207 TBS-T solution (1×TBS, 1\% BSA, 0.05\% Tween 20) for $2 \mathrm{~h}$ followed by $16 \mathrm{~h}$ 208 incubation at $4^{\circ} \mathrm{C}$ with mouse anti-rLsty-Stylicin1 polyclonal antibodies $(2.3 \mu \mathrm{g} / \mathrm{mL})$

209 [7]. After three washes in $1 \times$ TBS+0.05\% Tween 20 buffer, sections were incubated for $2103 \mathrm{~h}$ at room temperature with alkaline phosphatase-labeled rabbit anti-mouse IgG

211 (1:1000) (Thermo Scientific), followed by a $1 \mathrm{~h}$ incubation at room temperature in the

212 dark in a solution of $100 \mathrm{mM}$ Tris- $\mathrm{HCl}, 100 \mathrm{mM} \mathrm{NaCl}, 50 \mathrm{mM} \mathrm{MgCl}$ (pH 9.3) 
213 containing $0.175 \mathrm{mg} / \mathrm{mL}$ 5-bromo-4-chloro-3-indolyl phosphate (BCIP) (Sigma), 0.375

$214 \mathrm{mg} / \mathrm{mL}$ nitro blue tetrazolium (NBT) (Sigma) and $0.24 \mathrm{mg} / \mathrm{mL}$ levamisole (Sigma).

215 Negative controls consisted in replacing anti-rLsty-Stylicin1 antibodies with pre216 immune mouse serum or TBS-T solution.

217 Whole-mount immunofluorescence assays were conducted in midgut samples

218 from juvenile shrimp $(\mathrm{n}=3)$. Midguts were harvested by dissection, washed in ice-cold

219 Tris-saline solution and immediately fixed in $4 \%$ paraformaldehyde. Just after removal

220 of the intestinal content, midguts were longitudinally opened, washed in phosphate-

221 buffered saline (PBS: $137 \mathrm{mM} \mathrm{NaCl}, 2.7 \mathrm{mM} \mathrm{KCl}, 10 \mathrm{mM} \mathrm{Na} 2 \mathrm{HPO}_{4}, 2 \mathrm{mM} \mathrm{KH} \mathrm{PO}_{4}$,

$222 \mathrm{pH} 7.2)$ and blocked in PBS-T solution ( $1 \times \mathrm{PBS}, 1 \%$ BSA, $0.1 \%$ Triton $\mathrm{X}-100)$ for $3 \mathrm{~h}$

223 followed by $16 \mathrm{~h}$ incubation at $4^{\circ} \mathrm{C}$ with mouse anti-rLsty-Stylicin1 polyclonal 224 antibodies $(2.3 \mu \mathrm{g} / \mathrm{mL})$ [7]. Midguts were then washed 3 times with PBS-T solution for $22520 \mathrm{~min}$ and incubated for $4 \mathrm{~h}$ at room temperature with 4',6-diamidino-2-phenylindole 226 (DAPI) and FITC-conjugated anti-mouse secondary antibodies diluted at 1:500 227 (Thermo Scientific). Negative controls consisted in replacing the primary antibodies 228 with pre-immune mouse serum or PBS-T solution. The experiments were repeated three 229 times, and representative images were taken by confocal microscope (Leica DMI6000 B 230 Microscope).

2.8. Fluorescence-based reverse transcription real-time quantitative PCR (RT233 qPCR)

RT-qPCR reactions were performed in a final volume of $15 \mu \mathrm{L}$ containing $0.2 \mu \mathrm{M}$ of each primer (Table 1), 7.5 $\mu \mathrm{L}$ of Maxima SYBR Green/ROX qPCR Master Mix

236 (Thermo Scientific) and $1 \mu \mathrm{L}$ of cDNA. The RT-qPCR program was $95^{\circ} \mathrm{C}$ for $10 \mathrm{~min}$, 
237 followed by 40 cycles of $95^{\circ} \mathrm{C}$ for $15 \mathrm{~s}$ and $60^{\circ} \mathrm{C}$ for $60 \mathrm{~s}$. Melt curve analysis $\left(60-95^{\circ} \mathrm{C}\right.$ 238 at a temperature transition rate of $0.05^{\circ} \mathrm{C} / \mathrm{s}$ ) was performed to evaluate primer 239 specificity. Primer pair efficiencies (E) were calculated from 2-fold dilution series of 240 pooled cDNA for each primer pair. Primer pair efficiencies were calculated from the

241 given slopes in the StepOne software v2.3, according to the equation: $\mathrm{E}=10^{(-1 / \mathrm{slope})}$.

242 The eukaryotic translation elongation factor 1-alpha $(L v \mathrm{EF} 1 \alpha)$ and the ribosomal 243 proteins $L v \mathrm{~L} 40, L v \operatorname{RpS} 3 \mathrm{~A}$ and $L v \operatorname{RpS6}$ (Table 1) were used as reference genes of 244 expression data in circulating hemocytes. In midgut, $L v \mathrm{EF} 1 \alpha, L v \mathrm{~L} 40$ and $L v$ Actin were 245 used as reference genes for data normalization [13]. The relative expression levels of 246 Lvan-Stylicins were calibrated with the expression profile of circulating hemocytes or 247 midgut from naïve (unchallenged) shrimp, according to the $2^{-\Delta \Delta \mathrm{Cq}}$ method [14]. 248 Differences in gene expression were considered statistically significant at $P<0.05$ 249 (cutoff of 1.5-fold change in expression levels) using one-way ANOVA and Tukey's 250 multiple comparison test.

251 The transcript abundance of Lvan-Stylicins in three midgut portions (anterior, 252 middle and posterior) from Vibrio-challenged and naïve (unchallenged) shrimp was 253 quantified by RT-qPCR and normalized with the gene expression of $L v E F 1 \alpha, L v \operatorname{RpS} 3 \mathrm{~A}$, $L v \operatorname{RpS} 6$ and $L v$ Actin (Table 1). The relative expression levels were calibrated with the gene expression of each midgut portion from unchallenged shrimp and differences were considered statistically significant at $P<0.05$ (cutoff of 1.5 -fold change in expression 257 levels) using Student's t-test. 
The number of Lvan-STY gene copies in L. vannamei genome was estimated in

261 five individual shrimp by absolute quantification through the qPCR technique. qPCR

262 reactions were performed using specific primers (Table 1) and $80 \mathrm{ng}$ of gDNA as

263 template. The absolute quantification of the target genes (Lvan-STY1 and Lvan-STY2)

264 was calculated using a standard curve derived from 10-fold dilution series of plasmids

265 containing the DNA target sequences $\left(10^{7}\right.$ to $10^{3}$ plasmids $/ \mu L ; R^{2}=0.998$ and 0.999 for

266 Lvan-STY1 and Lvan-STY2, respectively). The transcript abundance of Lvan-Stylicin1

267 and Lvan-Stylicin2 in the circulating hemocytes of the same five shrimp individuals was

268 assessed by absolute quantification using $1 \mathrm{ng}$ of reverse-transcribed total RNA. The

269 absolute mRNA quantification was performed using the same method described for the

270 gene copy number estimation.

The comparison of the transcript abundance of Lvan-Stylicins between hemocytes

and midgut was assessed by RT-qPCR ( 3 pools of 4 animals per tissue) and normalized with the gene expression of $L v \mathrm{EF} 1 \alpha, L v \mathrm{RpS} 3 \mathrm{~A}$ and $L v \mathrm{RpS} 6$ (Table 1), according to the $2^{-\Delta \Delta \mathrm{Cq}}$ method [14]. Differences in gene expression between tissues were considered statistically significant at $P<0.05$ (cutoff of 1.5 -fold change in expression levels) using Student's t-test.

\subsection{Quantitative gene expression analysis during shrimp development}

Three biological replicates of different development stages of $L$. vannamei were

280 collected: fertilized eggs at $0-4 \mathrm{~h}(\mathrm{EI})$ and at 7-11 h post-spawning (EII), nauplius I and

281 V (NI and NV), protozoea I and III (ZI and ZIII), mysis I and III (MI and MIII) and 282 postlarvae aged of 2, 9 and 17 days (PL2, PL9 and PL17). Transcript levels of $L$. 283 vannamei stylicins during shrimp development were quantified by RT-qPCR and 
284 normalized with the gene expression of $L v \mathrm{RpS} 6$ and LvActin (Table 1), as previously 285 described [15]. Hemocyte samples from juveniles ( 3 pools of 5 animals) were used as

286 control for calibrating gene expression data. Genes were considered as "not expressed" 287 in a specific development stage when PCR amplification yielded no product (no 288 dissociation curves) whereas RT-qPCR reactions showing Cq values higher than the 289 limit of quantification (but that generated an expected dissociation curve profile) were 290 considered as "unquantifiable". Statistical significance was considered at $P<0.05$ by 291 one-way ANOVA followed by Tukey's multiple comparison test.

293 3. Results

294 3.1. L. vannamei stylicins comprise a diverse AAMP family

295 The transcriptomic analysis of the L. vannamei midgut (unpublished) has revealed 296 the presence of two nucleotide sequences (contigs: DN31608_c0_g1_i1 and 297 DN31608_c0_g1_i2) homologous to the stylicin antimicrobial peptides from the blue 298 shrimp L. stylirostris (Lsty-Stylicin1 and Lsty-Stylicin2). Both sequences correspond to 299 full-length transcripts that encode for precursors composed of a signal peptide followed 300 by a mature peptide containing 13 cysteine residues. The full-length stylicin sequences 301 from L. vannamei were cloned by PCR amplification from gDNA samples and re302 sequenced for confirmation. The nucleotide sequence corresponding to the contig 303 DN31608_c0_g1_i2 shared 86\% identity with Lsty-Stylicin1 (GenBank: EU177435) 304 whereas the contig DN31608_c0_g1_i1 shared 93\% identity with Lsty-Stylicin2 305 (GenBank: EU177437). Thus, those sequences from L. vannamei were designated as 306 Lvan-Stylicin1 (GenBank: MH108957) and Lvan-Stylicin2 (GenBank: MH108958), 307 respectively (Fig. 1A). 
The deduced amino acid sequences of Lvan-Stylicins start with a predicted 22-

309 residue signal peptide followed by an anionic mature peptide of 82 amino acid residues

310 (Fig. 1A; Table S1). Although Lvan-Stylicins contain no obvious protein domains, both

311 mature peptides are characterized by the presence of a proline-rich $\mathrm{N}$-terminal region

312 and a C-terminal region holding the 13 conserved cysteine residues found in $L$.

313 stylirostris stylicins and in the Mjap-Stylicin from M. japonicus. Lvan-Stylicins were

314 quite similar to each other and to stylicins from L. stylirostris (>80\% identity), but less

315 than $65 \%$ amino acid identity was observed between Lvan-Stylicins and Mjap-Stylicin.

316 In silico analysis of L. vannamei non-annotated databases publicly available on

317 GenBank led to the identification of different isoforms for each L. vannamei stylicin:

318 five for Lvan-Stylicin1 (GenBank: FE179060, FE156583, FE124653, FE125173 and

319 GETD01027084) and three for Lvan-Stylicin2 (GenBank: GETD01027083,

320 GETZ01053100 and GFRP01011277). Those sequences were identified in EST and

321 TSA libraries from multiple shrimp tissues, such as hemocytes, lymphoid organ, nerve

322 cord and hepatopancreas. Additionally, we included in this analysis the Vibrio

323 penaeicida-induced cysteine and proline-rich peptides ( $L v \mathrm{VICP} 1$ and $L v \mathrm{VICP} 2$ ),

324 stylicin homologues identified in L. vannamei by Wang and colleagues [9]. While Lvan-

325 Stylicin2 sequences differed only by synonymous and non-synonymous substitutions,

326 Lvan-Stylicin1 sequences showed two distinct lengths: 82 or 83 amino acid residues

327 (Fig. 1B; Table S1). Besides from the synonymous and non-synonymous substitutions,

328 Lvan-Stylicin1 peptides can be distinguished from each other by the presence/absence

329 of a tyrosine $(\mathrm{Y})$ or histidine $(\mathrm{H})$ residue at the position 51 of the precursor peptide (Fig.

330 1B). The 82-residue Lvan-Stylicin1 peptides showed a molecular weight of $8.83 \mathrm{kDa}$

331 and a calculated $\mathrm{p} I$ of 4.98 while the 83 -residue $L v a n$-Stylicin 1 peptides showed a 
332 molecular weight ranging from 8.97 to $9.02 \mathrm{kDa}$ and a calculated $\mathrm{p} I$ of 4.98 or 5.19

333 (Table S1). Comparatively, the mature Lvan-Stylicin2 peptides had a molecular weight

334 of about $9 \mathrm{kDa}$ and a calculated $\mathrm{p} I$ ranging from 4.47 to 4.69 (Table S1).

\subsection{L. vannamei stylicins are encoded by distinct genomic loci}

The genomic organization of L. vannamei stylicin genes (Lvan-STY1 and Lvan-

STY2) was investigated in two individual shrimp using PCR-based and cloning

strategies. Sanger DNA sequencing results showed that Lvan-Stylicins are encoded by

distinct genomic sequences, but share a similar structural gene organization (Fig. 2A).

Lvan-STY1 and Lvan-STY2 genes are composed by two exons interrupted by a single intron with a length of 217 bp and 205 bp, respectively (Fig. 2A). Both genomic DNA sequences followed the canonical GT/AG splicing recognition rule at the exon/intron boundaries (Fig. S1). In both genes, the first exon covers the 5'-untranslated region (UTR), the signal peptide and the first three residues of the mature peptide while the second exon encodes the remainder of the mature peptide sequence and the 3'-UTR. each other while the nucleotide sequence of their Lvan-STY2 genes differed in ten nucleotides: one in the first exon, five in the intron and four in the second exon (Fig. S1). The five nucleotide substitutions found in the coding sequence resulted in the change of two amino acid residues. The obtained genomic sequences were deposited in GenBank under the accession numbers MH108959 to MH108962.

Then, we asked whether Lvan-STY1 and Lvan-STY2 genes have the same number

354 of copies in L. vannamei genome. The relative gene copy number ratio of Lvan- 
356 number of Lvan-STY2 gene copies was $2.37 \pm 0.15$-fold higher than the number of copies

357 of the Lvan-STY1 gene (Fig. 2B). Finally, a phylogenetic analysis showed that the Lvan-

358 STY genes were placed in the same clade with the stylicin genes from L. stylirostris

359 (Lsty-STY1: EU177436 and Lsty-STY2: EU177437) (Fig. 2C). In this clade, Lvan-STY1

360 and Lsty-STY1 clustered together in a single group distinct to the STY2 genes (Fig. 2C).

361 Stylicin genes from P. monodon (Pmon-STY: NIUS012084699) and M. japonicus

362 (Mjap-STY: NIUR011088360) clustered in separate groups.

363

364

\subsection{Stylicins cluster into three distinct phylogenetic groups}

In silico mining of publicly accessible databases (EST, TSA and WGS) resulted in the identification of novel members of the Stylicin family in different penaeid species: Fenneropenaeus penicillatus (Fpen-Stylicin: GFRT01005742), M. japonicus (MjapStylicin: NIUR011088360) and P. monodon (Pmon-Stylicin: JZ892895, DW678047, and NIUS012084699). From our in silico analysis, stylicin sequences were only identified in penaeid shrimp species. All obtained sequences hold the 13 conserved cysteine residues at the C-terminal region (Fig. 3A).

Phylogenetic analysis revealed that the Stylicin family is a monophyletic group that evolved from a common ancestor gene. Phylogenetic trees constructed with nucleotide and predicted amino acid sequences shared similar topological structures. As

376 shown in Fig. 3B, stylicins clustered in three main clades. The first clade included only stylicin sequences from penaeid species from the genus Litopenaeus. In this clade, 
379 Pmon-Stylicins and Fpen-Stylicin clustered in a second phylogenetic group, Mjap-

380 Stylicins formed a separate clade from all stylicin sequences (Fig. 3B).

381

382 3.4. Stylicins are constitutively produced by hemocytes and intestinal cells

383 The gene expression distribution of L. vannamei stylicins was first evaluated in 384 eight different tissues of shrimp stimulated or not by the injection of heat-killed $V$. 385 harveyi. Results from the semiquantitative RT-PCR analysis evidenced the presence of 386 Lvan-Stylicin1 transcripts in circulating hemocytes, foregut, midgut and gills (Fig. 4). In 387 Vibrio-stimulated animals, Lvan-Stylicin1 gene expression was also detected in hindgut 388 and nerve cord. Comparatively, transcripts of Lvan-Stylicin2 were detected in 389 circulating hemocytes, foregut, midgut, hindgut, gills and nerve cord of both stimulated 390 and non-stimulated animals (Fig. 4). For both Lvan-Stylicins, no signals were observed 391 in muscle and hepatopancreas (Fig. 4).

392 To characterize the peptide localization of Lvan-Stylicins, immunohistochemistry 393 analysis was subsequently performed on sections of different shrimp tissues using 394 polyclonal antibodies raised against the rLsty-Stylicin1 from L. stylirostris [7]. Due to 395 the high degree of sequence conservation, anti-Lsty-Stylicin1 antibodies probably 396 recognized both Lvan-Stylicins. Stylicin immunoreactivity was found in individual cells

397 heterogeneously distributed across the shrimp tissues. In the cephalothorax, positive 398 immunoreactivity was especially pronounced in some cells present in the connective 399 tissue of the anterior midgut caecum (Fig. 5A-B). Based on morphological features, 400 those stylicin-positive cells are likely tissue-infiltrating hemocytes.

401 Besides those cells, stylicin immunoreactivity was also observed in the apical 402 region of the columnar epithelial cells lining the midgut and its anterior caecum (Fig. 
403 5A-B). Whole-mount immunofluorescence assays were further performed to confirm

404 the presence of stylicin peptides in those epithelial cells. Confocal images clearly

405 evidenced the presence of stylicin-containing granules located at the apical region of the

406 midgut columnar epithelial cells (Fig. 5C-E). No signals were observed in other cell

407 types of the shrimp body, thus the results of the semiquantitative RT-PCR analysis are

408 probably the consequence of the infiltration of stylicin-expressing hemocytes in shrimp

409 tissues. Altogether, results from both immunohistochemistry and whole-mount

410 immunofluorescence assays showed that Lvan-Stylicins are constitutively produced by

411 the hemocytes and by the columnar epithelial cells of the midgut.

412

413 3.5. Lvan-STY1 and Lvan-STY2 genes are simultaneously transcribed in a single

414 shrimp at different basal levels

415 Since Lvan-Stylicins are produced by both hemocytes and midgut cells, we

416 focused on determining the main site of stylicin expression in penaeid shrimp. Results

417 showed that the expression of Lvan-Stylicin1 and Lvan-Stylicin2 was, respectively,

418 52.5-fold and 62.2-fold higher in circulating hemocytes than in the midgut (Fig. 6A).

419 Next, the basal mRNA expression levels of the Lvan-STY1 and Lvan-STY2 genes were 420 analyzed in the circulating hemocytes of five individual shrimp by absolute 421 quantification. Interestingly, both Lvan-STY genes showed to be constitutively and 422 simultaneously transcribed in an individual shrimp, but at different transcriptional 423 levels. The basal expression of Lvan-STY2 was 3.69-fold higher than Lvan-STY1 (Fig. 424 6B). Besides, the basal mRNA levels of each gene showed to be also variable among 425 the individuals (Fig. 6B). For the Lvan-STY1 gene, differences in gene expression 
426 reached up to 3.78 -fold whereas variations up to 2.36 -fold were found in Lvan-STY2

427 gene expression.

428

3.6. The gene expression of $L$. vannamei stylicins is differentially modulated in

The gene expression profile of Lvan-Stylicins was further quantified by

fluorescence-based quantitative PCR (RT-qPCR) in shrimp hemocytes and midgut at 48

h after infections with two unrelated pathogens, the Gram-negative $V$. harveyi and the

WSSV. This time point was chosen on the basis of previous studies from our group $[10,13]$. Interestingly, while the expression of Lvan-Stylicin2 was induced in circulating hemocytes in response to the Vibrio infection (2.4-fold change), the expression of LvanStylicin1 was not modulated (Fig. 7). No increase in Lvan-Stylicin2 expression was observed following the injection of sterile seawater (aseptic injury control). Besides, both genes were not modulated after the viral infection. In contrast, the expression of

440 both genes was up-regulated in circulating hemocytes (2.5-fold change for Lvan441 Stylicin1 and 2.9-fold change for Lvan-Stylicin2) after the injection of a muscle tissue 442 homogenate prepared from WSSV-free shrimp (Fig. 7). In the midgut, the expression of Lvan-Stylicins was not regulated by the bacterial or by the viral infection (Fig. 7). alternative experimental infection method, mimicking a more natural route of bacterial 446 infection (per os challenge). Variations in gene expression of Lvan-Stylicins were 447 assessed by RT-qPCR in three midgut portions (anterior, middle and posterior). The 448 expression of both Lvan-Stylicins was up-regulated (2.89-fold change for Lvan- 
450 midgut (Fig. 8). By contrast, no increase in Lvan-Stylicin gene expression was observed 451 in the two first midgut portions (anterior and middle) in response to the oral Vibrio 452 challenge (Fig. 8).

3.7. L. vannamei stylicins show a different pattern of gene expression during shrimp development

We finally investigated the presence and the levels of stylicin transcripts in twelve developmental stages of L. vannamei, from fertilized eggs to larval (nauplius, protozoea and mysis) and postlarval stages, and also in circulating hemocytes from juveniles. Transcript levels of Lvan-Stylicin1 were detected at very low levels in late protozoea stages (ZIII), but its expression was only quantified from mysis III (MIII). Then, LvanStylicin1 expression increased gradually in the following developmental stages (Fig. 9).

On the other hand, Lvan-Stylicin2 transcripts were found to be present early in shrimp development (fertilized eggs at 7-11 h post-spawning). However, Lvan-Stylicin2 expression was only quantified from the protozoea III (ZIII) stage (Fig. 9). For both genes, the highest mRNA abundance was quantified in hemocytes from juvenile shrimp (Fig. 9).

\section{Discussion}

We showed here that L. vannamei stylicins comprise a diverse family of anionic antimicrobial peptides (AAMPs) whose genes are differentially regulated in hemocytes and midgut cells in response to infections. From the four gene-encoded AMPs described in penaeid shrimp, only stylicins have not been fully characterized in the Pacific white shrimp (L. vannamei) and this is the first study exploring the diversity of the stylicin 
474 family in terms of sequence and gene expression distribution and regulation. By taking

475 advantage of RNA-Seq technology, we have identified two stylicin homologues (Lvan-

476 Stylicin1 and Lvan-Stylicin2) in midgut transcriptomes of L. vannamei showing high

477 similarities to stylicins from the blue shrimp L. stylirostris [7]. From our in silico 478 analysis, stylicins form a diverse gene family in shrimp species of the genus

479 Litopenaeus, but not in other taxa of the family Penaeidae, such as Fenneropenaeus,

480 Penaeus and Marsupenaeus. Essentially, our results revealed that all known

481 Litopenaeus gene-encoded AMPs are present as diverse multigene families composed of 482 different members. For instance, while Litopenaeus penaeidins are composed of three 483 members (Litvan PEN1/2, Litvan PEN3 and Litvan PEN4), at least four and seven 484 members were identified in the crustin (Crustin $L v$, Crustin-like $L v, L v S W D$ and $485 L v$ SPLI) and in the ALF families (Litvan ALF-A to -G), respectively $[4,5,16]$. However, 486 unlike other gene-encoded AMPs from marine invertebrates, stylicins are exclusively 487 composed of anionic peptides. Interestingly, the spectrum of activity of these anionic 488 antimicrobials is restricted to filamentous fungi [7], even if their gene expression has 489 shown to be associated to shrimp survival to pathogenic Vibrio infections [6]. Likewise, 490 anionic peptides derived from the C-terminus of the shrimp respiratory protein 491 hemocyanin are also specific against fungi [17]. These hemocyanin-derived peptides, 492 named PvHCt, are able to bind and permeabilize fungal membranes [18]. To date, the 493 mechanism of action of stylicins and of other AAMPs is completely unknown. Actually, 494 in comparison to CAMPs, few scientific groups have attempted to study the subject of 495 AAMPs [3] and more functional studies are needed to achieve a more in-depth 496 understanding of these unconventional AMPs. 
We showed here that Lvan-Stylicin1 and Lvan-Stylicin2 are encoded by different

498 genomic loci. Nonetheless, the presence of distinct stylicin genes was only observed in

499 Litopenaeus species. Thus, it is likely that STY1 and STY2 are paralogous genes that

500 arose from a single gene duplication event before the speciation of the genus

501 Litopenaeus. Besides, although both Lvan-STY genes share a similar structural gene

502 organization, their copy numbers in L. vannamei genome showed to be variable, suggesting that they have followed independent duplication events after STY1-STY2 divergence. Apart from the two main stylicins members (Lvan-Stylicin1 and Lvanamino acids in length). No evidences for the presence of alternative splicing were found

507 in the Lvan-STY1 gene, and thus it is most likely that different alleles may occur for $L$. vannamei stylicin genes. Taken together, our results suggest that L. vannamei stylicins belong to a diverse multigenic and multiallelic family of AAMPs. Moreover, LvanSTY1 and Lvan-STY2 genes showed to be simultaneously transcribed in a single shrimp.

511 The different penaeidin and ALF members are also simultaneously expressed in an

512 individual shrimp $[16,19]$, and it would be of great interest to colocalize the four gene-

513 encoded AMP families in shrimp hemocytes and examine whether they function

514 synergistically to enhance their antimicrobial spectrum of activity. Synergic activities

515 have already been observed for AMPs from both vertebrate [20] and invertebrate 516 species [21,22], but unfortunately, no studies of this type have been addressed in 517 crustaceans.

518 One of the most important findings of this study is that the expression Lvan519 Stylicins is not limited to the immune cells (hemocytes) as observed for the other three 520 shrimp gene-encoded AMPs [4]. Both immunostaining and gene expression analysis 
521 revealed that Lvan-Stylicins are constitutively produced by the midgut columnar 522 epithelial cells and that their expression is induced in response to Vibrio infections. 523 Notably, the expression of Lvan-Stylicin was pronounced in the anterior midgut 524 caecum, an intestinal region primarily involved in the production, secretion and 525 activation of digestive enzymes [23]. Thus, it is plausive to hypothesize that Lvan-

526 Stylicins are secreted into the midgut lumen. This finding brings new insights into the 527 role of crustacean AMPs in the control of the gut microbiota and in shrimp intestinal 528 defenses. Indeed, the shrimp midgut lacks the cuticular lining found in the other 529 portions of the intestine (foregut and hindgut), representing a potential route of entry for 530 many pathogens into the hemocel. In a previous study, we showed that gut is an 531 important source for the expression of immune-related genes in penaeid shrimp [13], 532 thus the presence of stylicins in the midgut cells suggests the participation of these antimicrobial effectors in the first intestinal line of defense. Interestingly, the expression

534 of some ALF members showed to be involved in the maintenance of the microbiota 535 residing in the shrimp hemolymph [24]. Taken all together, our results highlight the 536 importance of stylicins in both hemolymph-based and gut-based immunities. genes are differentially regulated after infections. Such diversity in gene expression

539 regulation was previously reported for the different members of the L. vannamei ALF 540 family in response to fungal infections [25]. Interestingly, while some AMPs such as 541 Lvan-Stylicin1, penaeidins [26], Litvan ALF-A [25] and Type II crustins [27] are not-

542 regulated in response to infections, the expression of other L. vannamei AMPs (Lvan543 Stylicin2 and other ALF members) is induced in immune cells to improve host 544 antimicrobial responses against pathogens. As elegantly shown by Wang et al. [9], the 
545 gene expression of most shrimp AMPs, including penaeidins, Type II crustins and 546 stylicins ( $L v$ VICPs), is controlled by the IMD/NF- $\kappa \mathrm{B}$ pathway, an evolutionarily

547 conserved signaling cascade involved in the regulation of the antimicrobial responses of 548 arthropods. On the other hand, the expression of almost all shrimp AMPs, including 549 Lvan-Stylicins, can be drastically affected in circulating hemocytes during lethal 550 infections [10]. Unlike the Mjap-Stylicin from the kuruma prawn M. japonicus [8], 551 Lvan-Stylicins were not modulated neither in circulating hemocytes nor in midgut by 552 the WSSV. This result could be probably due to the time course response of Lvan553 Stylicins in those shrimp tissues. On the other hand, both Lvan-STY genes have been 554 shown to be responsive to a tissue homogenate prepared from shrimp muscle (injury 555 control for the WSSV infection). This finding strongly suggests that Lvan-Stylicins are 556 induced in response to danger/damage-associated molecular patterns (DAMPs) and that these AAMPs could be involved in early inflammation and in wound healing processes as proposed for penaeidins [26].

L. vannamei stylicin genes showed to be differentially regulated not only in

560 response to infections, but also during shrimp development. Interestingly, Lvan-

561 Stylicin2 and the M. japonicus stylicin showed a very similar pattern of gene expression during shrimp development [8]. Comparatively, Lvan-Stylicin1 expression was quite

563 similar to that observed for other L. vannamei AMPs, such as Litvan PEN1/2, Litvan

564 PEN4 and Litvan ALF-D [15]. Apart from that, we cannot discard the possibility of 565 these changes in gene expression could be the result of the differences in the mRNA 566 basal levels observed between the Lvan-STY genes. Indeed, the detection of stylicin transcripts, as well as of other gene-encoded AMPs, highlights the importance of these antimicrobial effectors during shrimp development. 
570

571

572

573

574

575

576

577

578

579

580

581

582

583

584

585

586

587

588

589

590

591

\section{Conclusions}

In conclusion, we showed that the stylicin family from shrimp species of the genus Litopenaeus is composed of two members encoded by distinct genomic loci that exhibit different patterns of gene expression distribution and regulation. According to the best of our knowledge, this is the first evidence for the expression of a shrimp geneencoded AMP in other tissues than the hemocytes. Even though the expression of stylicins has been shown to be a marker of shrimp survival to pathogenic Vibrio infections, the role of these effectors in shrimp immune defense is still largely unknown. The application of RNAi-based methods could make significant contributions to understanding the significance of the molecular and transcriptional diversity of Litopenaeus stylicins in host-microbe interactions.

\section{Acknowledgments}

We are grateful to the Laboratory of Marine Shrimp (Federal University of Santa Catarina - UFSC) for providing the shrimp used in this study and to Fabio S Ribeiro for his technical assistance in the whole-mount immunofluorescence experiments. The authors are also thankful to the Electronic Microscopy Central Laboratory (LCMEUFSC) and the Multiuser Laboratory of Biology Studies (LAMEB-UFSC). This work was supported by the Brazilian funding agencies CNPq (MEC/MCTI/CAPES/CNPq/FAPs PVE 401191/2014-1 and MCTI/CNPq Universal 406530/2016-5) and CAPES (CIMAR 1974/2014). P Schmitt was funded by FONDECYT grant 11150009. ND Farias and GM Matos were supported by 
592 scholarships provided by FAPESC while N Argenta received a scholarship provided by

593 CNPq. M Falchetti and C Barreto were supported by fellowships provided by CAPES.

594

\section{References}

596 [1] Brogden KA. Antimicrobial peptides: pore formers or metabolic inhibitors in bacteria? Nat Rev Microbiol 2005;3:238-50. doi:10.1038/nrmicro1098.

598 [2] Yount NY, Bayer AS, Xiong YQ, Yeaman MR. Advances in antimicrobial peptide immunobiology. Biopolymers 2006;84:435-58. doi:10.1002/bip.20543.

600 [3] Harris F, Dennison S, Phoenix D. Anionic antimicrobial peptides from eukaryotic organisms. Curr Protein Pept Sci 2009;10:585-606.

603 doi:10.2174/138920309789630589.

[4] Destoumieux-Garzón D, Rosa RD, Schmitt P, Barreto C, Vidal-Dupiol J, Mitta 604 $\mathrm{G}$, et al. Antimicrobial peptides in marine invertebrate health and disease. Philos Trans R Soc B Biol Sci 2016;371:20150300. doi:10.1098/rstb.2015.0300.

[5] Rosa RD, Barracco MA. Antimicrobial peptides in crustaceans. Invertebr Surviv 607 J 2010;7:262-84.

608 [6] de Lorgeril J, Saulnier D, Janech MG, Gueguen Y, Bachère E. Identification of 609 genes that are differentially expressed in hemocytes of the Pacific blue shrimp ( Litopenaeus stylirostris ) surviving an infection with Vibrio penaeicida. Physiol Genomics 2005;21:174-83. doi:10.1152/physiolgenomics.00281.2004.

612 [7] Rolland JL, Abdelouahab M, Dupont J, Lefevre F, Bachère E, Romestand B. 613 Stylicins, a new family of antimicrobial peptides from the Pacific blue shrimp 614 Litopenaeus stylirostris. Mol Immunol 2010;47:1269-77. doi:10.1016/j.molimm.2009.12.007. 
616 [8] Liu H, Wang J, Mao Y, Liu M, Niu S, Qiao Y, et al. Identification and expression analysis of a novel stylicin antimicrobial peptide from Kuruma shrimp (Marsupenaeus japonicus). Fish Shellfish Immmunology 2015;47:817-23. doi:10.1016/j.fsi.2015.09.044.

620 [9] Wang PH, Wan DH, Gu ZH, Qiu W, Chen YG, Weng SP, et al. Analysis of expression, cellular localization, and function of three inhibitors of apoptosis (IAPs) from Litopenaeus vannamei during WSSV infection and in regulation of antimicrobial peptide genes (AMPs). PLoS One 2013;8:e72592. doi:10.1371/journal.pone.0072592.

[10] Goncalves P, Guertler C, Bachère E, de Souza CRB, Rosa RD, Perazzolo LM. Molecular signatures at imminent death: hemocyte gene expression profiling of shrimp succumbing to viral and fungal infections. Dev Comp Immunol 2014;42:294-301. doi:10.1016/j.dci.2013.09.017.

[11] Pilotto M, Goncalves A, Vieira F, Seifert W, Bachère E, Rosa RD, et al. Exploring the Impact of the Biofloc Rearing System and an Oral WSSV Challenge on the Intestinal Bacteriome of Litopenaeus vannamei. Microorganisms 2018;6:83. doi:10.3390/microorganisms6030083.

[13] Silveira AS, Matos GM, Falchetti M, Ribeiro FS, Bressan A, Bachère E, et al. An immune-related gene expression atlas of the shrimp digestive system in response to two major pathogens brings insights into the involvement of hemocytes in gut immunity. Dev Comp Immunol 2018;79:44-50. 
doi:10.1016/j.dci.2017.10.005.

641 [14] Livak KJ, Schmittgen TD. Analysis of relative gene expression data using real642 time quantitative PCR and the 2(-Delta Delta C(T)) method. Methods 2001;25:402-8. doi:10.1006/meth.2001.1262.

644 [15] Quispe RL, Justino EB, Vieira FN, Jaramillo ML, Rosa RD, Perazzolo LM. Transcriptional profiling of immune-related genes in Pacific white shrimp (Litopenaeus vannamei) during ontogenesis. Fish Shellfish Immunol 2016;58:103-7. doi:10.1016/j.fsi.2016.09.024.

[16] Matos GM, Schmitt P, Barreto C, Farias ND, Toledo-Silva G, Guzmán F, et al. Massive Gene Expansion and Sequence Diversification Is Associated with Diverse Tissue Distribution, Regulation and Antimicrobial Properties of AntiLipopolysaccharide Factors in Shrimp. Mar Drugs 2018;16:381. doi:10.3390/md16100381.

[17] Destoumieux-Garzón D, Saulnier D, Garnier J, Jouffrey C, Bulet P, Bachère E. Crustacean Immunity. J Biol Chem 2001;276:47070-7. doi:10.1074/jbc.M103817200.

[18] Petit VW, Rolland JL, Blond A, Cazevieille C, Djediat C, Peduzzi J, et al. A 657 hemocyanin-derived antimicrobial peptide from the penaeid shrimp adopts an alpha-helical structure that specifically permeabilizes fungal membranes.

660 [19] Cuthbertson BJ, Shepard EF, Chapman RW, Gross PS. Diversity of the 661 662 penaeidin antimicrobial peptides in two shrimp species. Immunogenetics 2002;54:442-5. doi:10.1007/s00251-002-0487-z.

663 [20] Yan H, Hancock REW. Synergistic Interactions between Mammalian 
664

665

666

667

668

669

670

671

672

673

674

675

676

677

678

679

680

681

682

683

684

685

686

687

Antimicrobial Defense Peptides. Antimicrob Agents Chemother 2001;45:155860. doi:10.1128/AAC.45.5.1558-1560.2001.

[21] Schmitt P, de Lorgeril J, Gueguen Y, Destoumieux-Garzón D, Bachère E. Expression, tissue localization and synergy of antimicrobial peptides and proteins in the immune response of the oyster Crassostrea gigas. Dev Comp Immunol 2012;37:363-70. doi:10.1016/j.dci.2012.01.004.

[22] Marxer M, Vollenweider V, Schmid-Hempel P. Insect antimicrobial peptides act synergistically to inhibit a trypanosome parasite. Philos Trans R Soc B Biol Sci 2016;371:20150302. doi:10.1098/rstb.2015.0302.

[23] McGaw IJ, Curtis DL. A review of gastric processing in decapod crustaceans. J Comp Physiol 2013;183:443-65. doi:10.1007/s00360-012-0730-3.

[24] Wang XW, Xu JD, Zhao XF, Vasta GR, Wang JX. A shrimp C-type lectin inhibits proliferation of the hemolymph microbiota by maintaining the expression of antimicrobial peptides. J Biol Chem 2014;289:11779-90. doi:10.1074/jbc.M114.552307.

[25] Rosa RD, Vergnes AA, de Lorgeril J, Goncalves P, Perazzolo LM, Sauné L, et al. Functional divergence in shrimp anti-lipopolysaccharide factors (ALFs): from recognition of cell wall components to antimicrobial activity. PLoS One 2013;8:e67937. doi:10.1371/journal.pone.0067937.

[26] Destoumieux D, Muñoz M, Cosseau C, Rodriguez J, Bulet P, Comps M, et al. Penaeidins, antimicrobial peptides with chitin-binding activity, are produced and stored in shrimp granulocytes and released after microbial challenge. J Cell Sci 2000;113:461-9. doi:10.1016/j.bbagen.2015.12.010.

[27] Barreto C, Coelho JR, Yuan J, Xiang J, Perazzolo LM, Rosa RD. Specific 
691 
692 Appendix A. Supplementary data

693 Supplemental Table S1. Biochemical properties of stylicin antimicrobial peptides from 694 penaeid shrimp.

695 Supplemental Figure S1. Multiple nucleotide alignment of Lvan-STY1 and Lvan-STY2 696 genes from two single shrimp: individual \#1 (Lvan-STY1: MH108959; Lvan-STY2: 697 MH108960) and individual \#2 (Lvan-STY1: MH108961; Lvan-STY2: MH108962). Exon 698 sequences are in bold. Nucleotide substitutions and the canonical GT/AG splice site 699 junctions are shadowed with black and gray backgrounds, respectively. 


\section{$701 \quad$ Tables}

702 Table 1. Nucleotide sequences of primers used in this study.

\begin{tabular}{|c|c|c|c|}
\hline Gene & Forward primer (5'-3') & Reverse primer (5'-3') & $\overline{\text { Amplicon }}$ \\
\hline \multicolumn{4}{|c|}{ Primers for molecular cloning and sequencing } \\
\hline Lvan-STY1 & CTGGACGCATCCCTGCTG & TGCGCCTTCGTTCTCTTTATC & 571 bp \\
\hline Lvan-STY2 & GCTGTACTGCTCCTGTGTAG & CTTCGTTCTCGCTTCTTTATCC & 589 bp \\
\hline \multicolumn{4}{|c|}{ Primers for tissue distribution analysis (RT-PCR) } \\
\hline Lvan-Stylicin 1 & CACAAGAGTGCCCACCGTG & ACATTCGCAGTTATGGTAGCC & $125 \mathrm{bp}$ \\
\hline Lvan-Stylicin2 & CACAAGAGTGCCCACCGTG & CACACAGGCTGCCGACATAA & $151 \mathrm{bp}$ \\
\hline$L v$ Actin & TAATCCACATCTGCTGGAAGGTGG & TCACCAACTGGGATGACATGG & 846 bp \\
\hline \multicolumn{4}{|c|}{ Primers for absolute and relative quantification analyses ( $q P C R$ and $R T-q P C R$ ) } \\
\hline Lvan-Stylicin 1 & CACAAGAGTGCCCACCGTG & ACATTCGCAGTTATGGTAGCC & 125 bp \\
\hline Lvan-Stylicin2 & CACAAGAGTGCCCACCGTG & CACACAGGCTGCCGACATAA & $151 \mathrm{bp}$ \\
\hline LvActin & CCACGAGACCACCTACAAC & AGCGAGGGCAGTGATTTC & $142 \mathrm{bp}$ \\
\hline$L v \mathrm{EF} 1 \alpha$ & TGGCTGTGAACAAGATGGACA & TTGTAGCCCACCTTCTTGACG & $103 \mathrm{bp}$ \\
\hline$L v \mathrm{~L} 40$ & GAGAATGTGAAGGCCAAGATC & TCAGAGAGAGTGCGACCATC & 104 bp \\
\hline$L v \operatorname{RpS} 3 \mathrm{~A}$ & GGCTTGCTATGGTGTGCTCC & TCATGCTCTTGGCTCGCTG & $101 \mathrm{bp}$ \\
\hline$L v \mathrm{RpS} 6$ & AGCAGATACCCTTGGTGAAG & GATGCAACCACGGACTGAC & $193 \mathrm{bp}$ \\
\hline
\end{tabular}


705 Figure captions

706 Figure 1. (A) Nucleotide and deduced amino acid sequences (one letter code) of Lvan-

707 Stylicin1 (GenBank: MH108957) and Lvan-Stylicin2 (GenBank: MH108958). The

708 predicted signal peptides are in bold and underlined. Asterisks $\left(^{*}\right)$ mark the stop codon.

709 (B) Amino acid sequence alignments of stylicins from penaeid shrimp species from the

710 genus Litopenaeus (Lvan: L. vannamei and Lsty: L. stylirostris). Identical amino acid

711 residues are highlighted in black while specific amino acid residues found in Stylicin1

712 and Stylicin2 peptides are highlighted in blue and yellow, respectively. Triangles ( $\boldsymbol{\nabla})$

713 indicate the 13 conserved cysteine residues. GenBank accession numbers are indicated

714 in brackets. The sequences of the Vibrio penaeicida-induced cysteine and proline-rich

715 peptides ( $L v \mathrm{VICP} 1$ and $L v \mathrm{VICP} 2)$ were obtained from [9].

716

717 Figure 2. (A) Not-to-scale schematic representation of stylicin genes from Litopenaeus

718 vannamei (Lvan-STY1 and Lvan-STY2). Boxes represent the exons and the line between

719 boxes represents the intron. Numbers indicate the length of exons and introns in base

720 pairs. (B) Estimation of the copy number of Lvan-STY genes in five individual shrimp.

721 The absolute quantification was assessed by qPCR using a standard curve derived from

722 10-fold dilution series of plasmids containing each target gene. Results are presented as

723 the ratio of the abundance of Lvan-STY2 gene copies per ng of gDNA to that of Lvan-

724 STY1. (C) Structural organization and phylogenetic relationship of STY genes from

725 penaeid shrimp: Litopenaeus vannamei (Lvan-STY1: MH108959 and MH108961; Lvan-

726 STY2: MH108960 and MH108962), Litopenaeus stylirostris (Lsty-STY1: EU177436;

727 Lsty-STY2: EU177437), Penaeus monodon (Pmon-STY: NIUS012084699) and

728 Marsupenaeus japonicus (Mjap-STY: NIUR011088360). The cladogram at the left of 
729 the figure indicates the phylogenetic relationship of $S T Y$ genes. Pink and yellow boxes

730 indicate the position of the signal peptides and the mature stylicins in the exons,

731 respectively, while the black lines indicate the introns.

732

733 Figure 3. (A) Amino acid sequence alignments of mature peptides of stylicins. Identical

734 amino acid residues are highlighted in black. Triangles $(\boldsymbol{\nabla})$ indicate the 13 conserved 735 cysteine residues. GenBank accession numbers are indicated in brackets. (B)

736 Phylogenetic analysis of stylicins from penaeid shrimp. The tree was constructed using 737 the Maximum Likelihood method with bootstrap values calculated from 1,000 trees.

738 Sequences included in analyses were the following: Litopenaeus vannamei (Lvan-

739 Stylicin1: MH108957, MH108959, MH108961, FE179060, FE156583, FE124653,

740 FE125173, GETD01027084 and LvVICP1; Lvan-Stylicin2: MH108958, MH108960,

741 MH108962, GETD01027083, GETZ01053100, GFRP01011277 and LvVICP2),

742 Litopenaeus stylirostris (Lsty-Stylicin1: EU177435, EU177436 and GM615897; Lsty-

743 Stylicin2: EU177437), Fenneropenaeus penicillatus (Fpen-Stylicin: GFRT01005742),

744 Penaeus monodon (Pmon-Stylicin: JZ892895, DW678047, DW678039, DT366712,

745 DW042940, GW996588, GEEP01015864, GEME01013089 and NIUS012084699) and

746 Marsupenaeus japonicus (Mjap-Stylicin: KR063277 and NIUR011088360).

747

748 Figure 4. Gene expression distribution of Litopenaeus vannamei stylicins (Lvan-

749 Stylicin1 and Lvan-Stylicin2) in different tissues from naïve (N) and Vibrio-stimulated

750 (S) shrimp. Gene expression analysis was performed by semiquantitative RT-PCR using

751 the $\beta$-actin gene ( $L v$ Actin) as an endogenous expression control. The figure (not-to-

752 scale) shown at the top of the figure indicates the anatomic location of shrimp tissues: 
753 foregut (FG), hepatopancreas (HP), midgut (MG), hindgut (HG), circulating hemocytes 754 (HE), muscle (ML), gills (GL) and nerve cord (NC).

755

756 Figure 5. (A) Immunodetection of Lvan-Stylicin peptides in shrimp tissues by 757 immunohistochemistry. Stylicin immune reactivity was observed in hemocytes 758 infiltrating the connective tissue (arrows) and in the columnar epithelium of the midgut. 759 The figure (not-to-scale) shown at the top panel indicates the anatomic location of 760 shrimp tissues: anterior midgut caecum (AMC), midgut (MG) and hepatopancreas (HP).

761 Scale bars $=100 \mu \mathrm{m}$. (B) A magnification of the anterior midgut caecum. The arrows 762 indicate stylicin-expressing hemocytes infiltrating connective tissues. Negative controls 763 consisted in replacing primary antibodies with pre-immune mouse serum (bottom 764 panel). Scale bars $=100 \mu \mathrm{m}$. (C) Scanning confocal microscopy images of the 765 immunodetection (whole mount immunofluorescence staining) of Lvan-Stylicin 766 peptides present in granules located at the apical region of the midgut columnar 767 epithelial cells. (D) Nuclei of the midgut columnar epithelial cells stained with DAPI.

768 (E) Merged images of the stylicin-containing granules (green) and the nuclei (blue) of 769 the midgut columnar epithelial cells. Scale bars $=20 \mu \mathrm{m}$.

770

771 Figure 6. (A) Quantitative comparison of the relative abundance of Lvan-Stylicin1 772 (white bars) and Lvan-Stylicin2 (black bars) transcripts in circulating hemocytes (HE) 773 and midgut (MG). Results are presented as mean \pm standard deviation of relative 774 expressions (three biological replicates) and statistical differences are indicated by 775 asterisks (*) (Student's t-test, $P<0.05)$. (B) Transcript abundance of Lvan-Stylicins in

776 five individual shrimp. The absolute quantification was assessed by qPCR using a 
777 standard curve derived from 10-fold dilution series of plasmids containing each target

778 gene. Results are presented as the ratio of the abundance of Lvan-Stylicin2 transcripts

779 per ng of total RNA to that of Lvan-Stylicin1. The $\beta$-actin gene (LvActin) was used as

780 endogenous expression control for each individual shrimp (lower panel).

781

782 Figure 7. Relative gene expression profile of Lvan-Stylicin1 (white bars) and Lvan-

783 Stylicin2 (black bars) in circulating hemocytes and midgut of shrimp at $48 \mathrm{~h}$ after

784 experimental infections with the Gram-negative Vibrio harveyi ATCC $14126\left(6 \times 10^{7}\right.$

785 CFU/animal) or the White spot syndrome virus (WSSV: $3 \times 10^{2}$ viral particles/animal).

786 Results are presented as mean \pm standard deviation of relative expressions (three

787 biological replicates) and statistical differences are indicated by asterisks (*) (one-way

788 ANOVA/Tukey, $P<0.05)$. W-free: tissue homogenate inoculum prepared from WSSV-

789 free shrimp.

790

791 Figure 8. Relative gene expression profile of Lvan-Stylicin1 and Lvan-Stylicin2 in three

792 portions of shrimp midgut (anterior, middle and posterior) at $21 \mathrm{~h}$ after the oral

793 administration of $7.5 \times 10^{5}$ CFU/animal of live $V$. harveyi ATCC 14126. Results are

794 presented as mean \pm standard deviation of relative expressions (three biological

795 replicates) and statistical differences are indicated by asterisks (*) (Student's t-test, $P<$

796 0.05). The figure (not-to-scale) shown at the top of the figure indicates the anatomic

797 location of the three midgut portions from naïve (white bars) and Vibrio-challenged

798 (black bars) shrimp.

799 
800 Figure 9. Gene expression profile of Litopenaeus vannamei stylicins during shrimp

801 development. EI: fertilized eggs at 0-4 h post-spawning; EII: fertilized eggs at 7-11 h

802 post-spawning; NI: nauplius I; NV: nauplius V; ZI: protozoea I; ZIII: protozoea III; MI:

803 mysis I; MIII: mysis III; PL2: postlarva 2; PL9: postlarva 9; PL17: postlarva 17. The

804 red dotted line indicates the basal expression level in hemocytes from juvenile shrimp

805 while the solid blue underline highlights the stages at which the gene expression was

806 detected (valid dissociation curve profile) but not quantified (Cq values higher than the

807 limit of quantification). Results are presented as mean \pm standard deviation (three

808 biological replicates). Different letters indicate significant differences among the

809 development stages while asterisks $(*)$ shows significant differences between each

810 developmental stage and hemocytes from juveniles (one-way ANOVA/Tukey, $P<$ $8110.05)$. 


\section{A}

atgaagacctacagtcaggtctctgtttttgtcttattggttgcgatcgcgcacacgtca

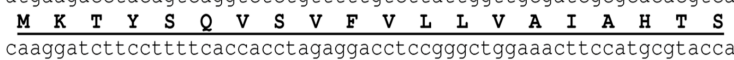
$\begin{array}{llllllllllllllllllll}Q & G & G & S & F & S & P & P & R & G & P & P & G & W & K & L & P & C & V & P\end{array}$ caagagtgcccaccgtgcccatatgatgatgagtgtccgaagtgcggtggattcccggtg

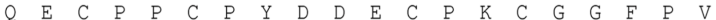
tgtcacgaggtgtgcaccgatattagtatatcatgtgaatgcggctaccatagctgcgaa $\begin{array}{llllllllllllllllllll}C & H & E & V & C & T & D & I & S & I & S & C & E & C & G & Y & H & S & C & E\end{array}$ tgtccgcggcctgtgtgtgagccgtgcgaaagtcccatcgccgagttgatcaaaaaggga $\begin{array}{llllllllllllllllllll}C & P & R & P & V & C & E & P & C & E & S & P & I & A & E & L & I & K & K & G\end{array}$ ggctataaaggataa

B Lvan [MHETD01027] Lvan [MH108959]

LIvan [MH108961]

$\subseteq \quad$ Lvan [FE124653]

LVVICP1

خ Lvan [FE156583]

Lsty [EU177435]

Lsty [GM615897]

Lsty [EU177436]

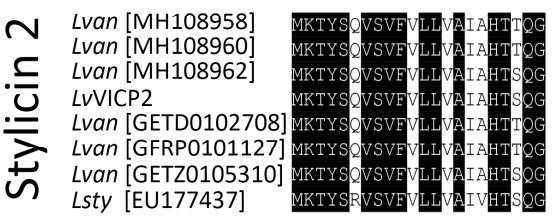

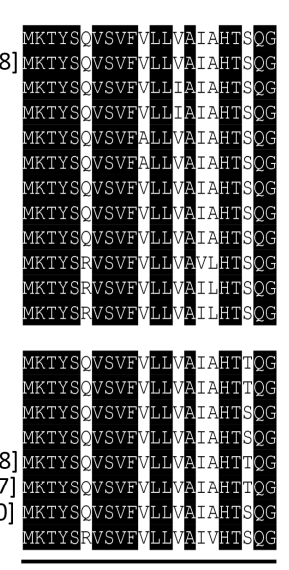

Signal peptide

\section{Lvan-Stylicin2}

atgaagacctacagtcaggtctctgtttttgtcttattggttgcgatcgcgcacacgaca \begin{tabular}{llllllllllllllllllll}
$\mathbf{M}$ & $\mathbf{K}$ & $\mathbf{T}$ & $\mathbf{Y}$ & $\mathbf{S}$ & $\mathbf{Q}$ & $\mathbf{V}$ & $\mathbf{S}$ & $\mathbf{V}$ & $\mathbf{F}$ & $\mathbf{V}$ & $\mathbf{L}$ & $\mathbf{L}$ & $\mathbf{V}$ & $\mathbf{A}$ & $\mathbf{I}$ & $\mathbf{A}$ & $\mathbf{H}$ & $\mathbf{T}$ & $\mathbf{T}$ \\
\hline
\end{tabular} $\begin{array}{lllllllllllllllllllll}\mathbf{Q} & G & S & S & F & S & P & P & G & R & L & P & G & W & E & P & P & C & V & P\end{array}$ caagagtgcccaccgtgcccatatgatgatgagtgtccgaagtgcgaggaagtaccggc C E C P P C P Y D D I C P K C E E V P A tgtgaggagtgccccgatattcatataggatgtgactgccctttctaccacagctgctta $\begin{array}{lllllllllllllllllllll}C & E & E & C & P & D & I & H & I & G & C & D & C & P & F & Y & H & S & C & L\end{array}$ gtcggcagcctgtgtgtgagccgtgcgaaagtcccatcgccgagttgatcaaaaaggga $\begin{array}{llllllllllllllllllll}C & R & \& & P & V & C & E & P & C & E & S & P & I & A & E & L & I & K & K & G\end{array}$ ggctataaaggataa

G Y K G *
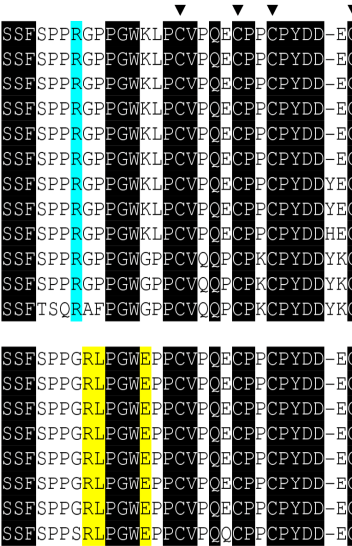

Proline-rich
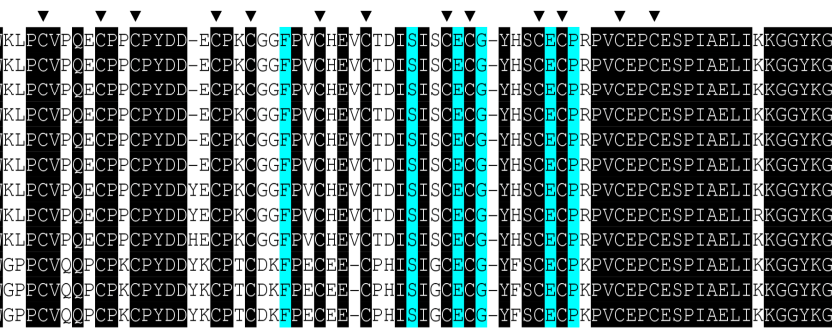

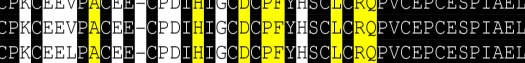
PVCEPCESPIAE VVEPCESPIAE PVCEPCESPIAETIAET VCEPCESPIAELI

Cysteine-rich 
A
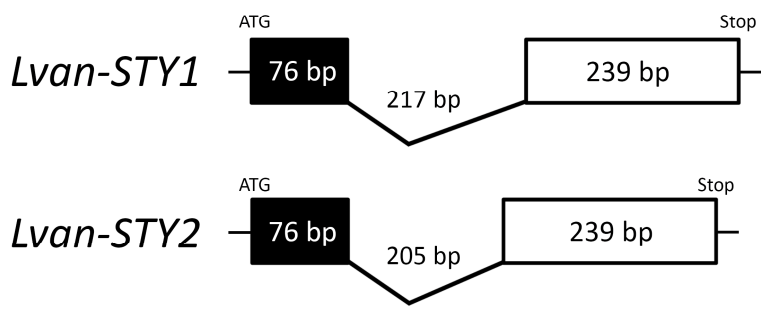

Exon $1 \square$ Exon 2 VIntron

B

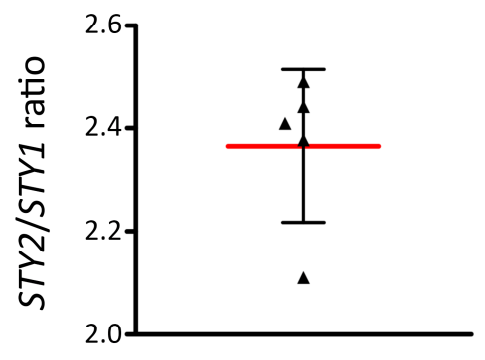

individuals

C

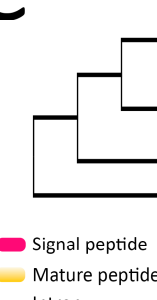

— Lsty-STY1

Lvan-STY1

Lsty-STY2

Pmon-STY

Mjap-STY

Mature peptid

$5^{\prime}$

$5^{\prime}$

$\frac{1}{100 \mathrm{bp}}$

$300 \mathrm{bp}$

$\frac{1}{400 \mathrm{bp}}$

$500 \mathrm{bp}$ 


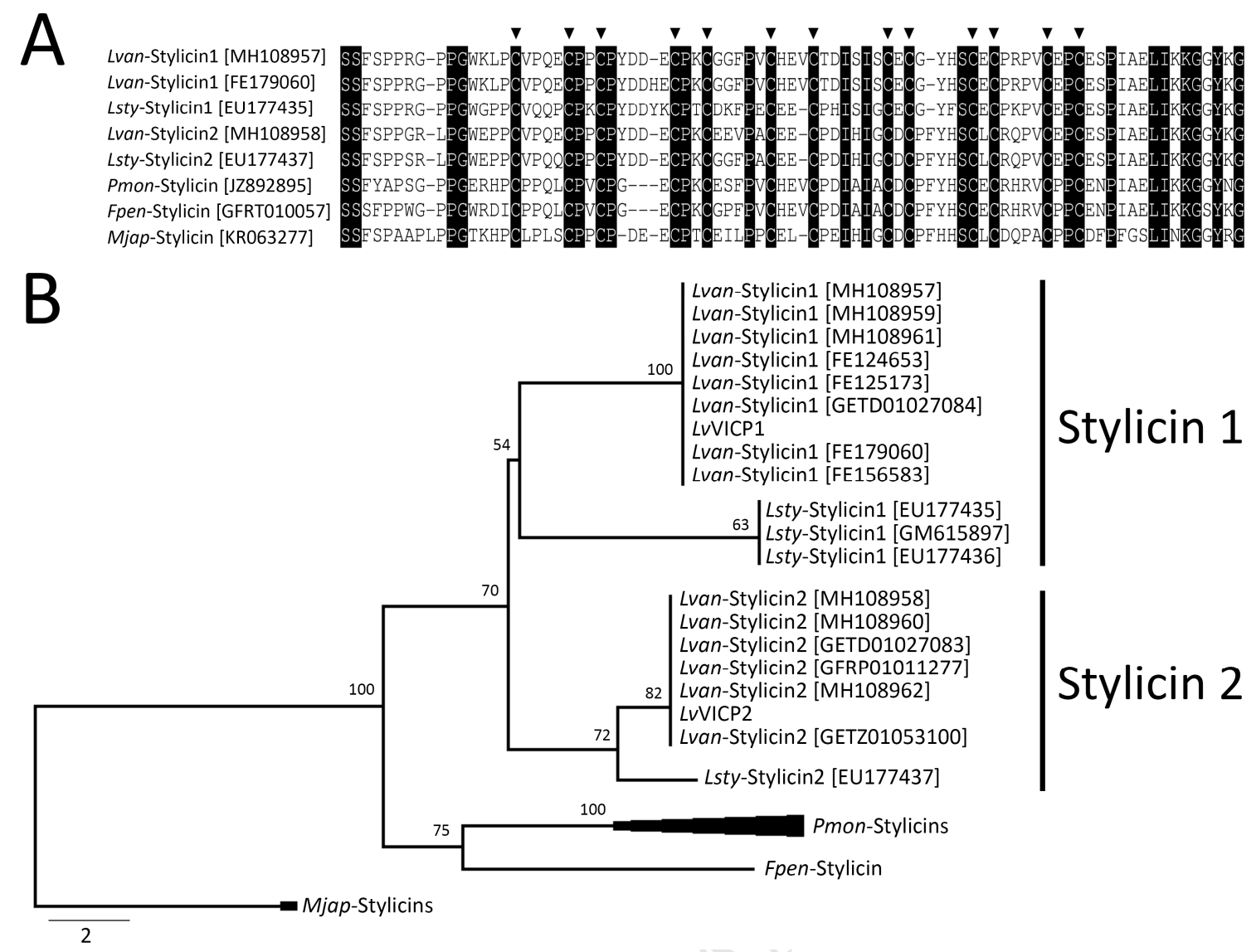




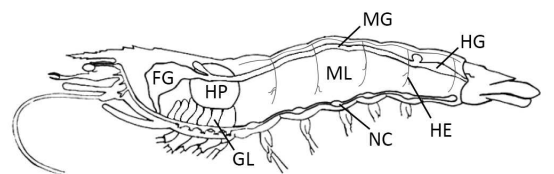

FG $\mathrm{HP}$ MG $\mathrm{HG}$ HE ML GL $\frac{\mathrm{NC}}{N S}$

$\overline{N S} \frac{\mathrm{NS}}{\mathrm{NS}} \frac{\mathrm{NS}}{\mathrm{NS}} \frac{\mathrm{NS}}{\mathrm{NS}} \frac{\mathrm{NS}}{-1}$

Lvan-Stylicin1

Lvan-Stylicin2 - _ _- - - - - - $151 \mathrm{bp}$

LvActin - - - - - - - - - - - - $-846 \mathrm{bp}$ 


\section{ACCEPTED MANUSCRIPT}

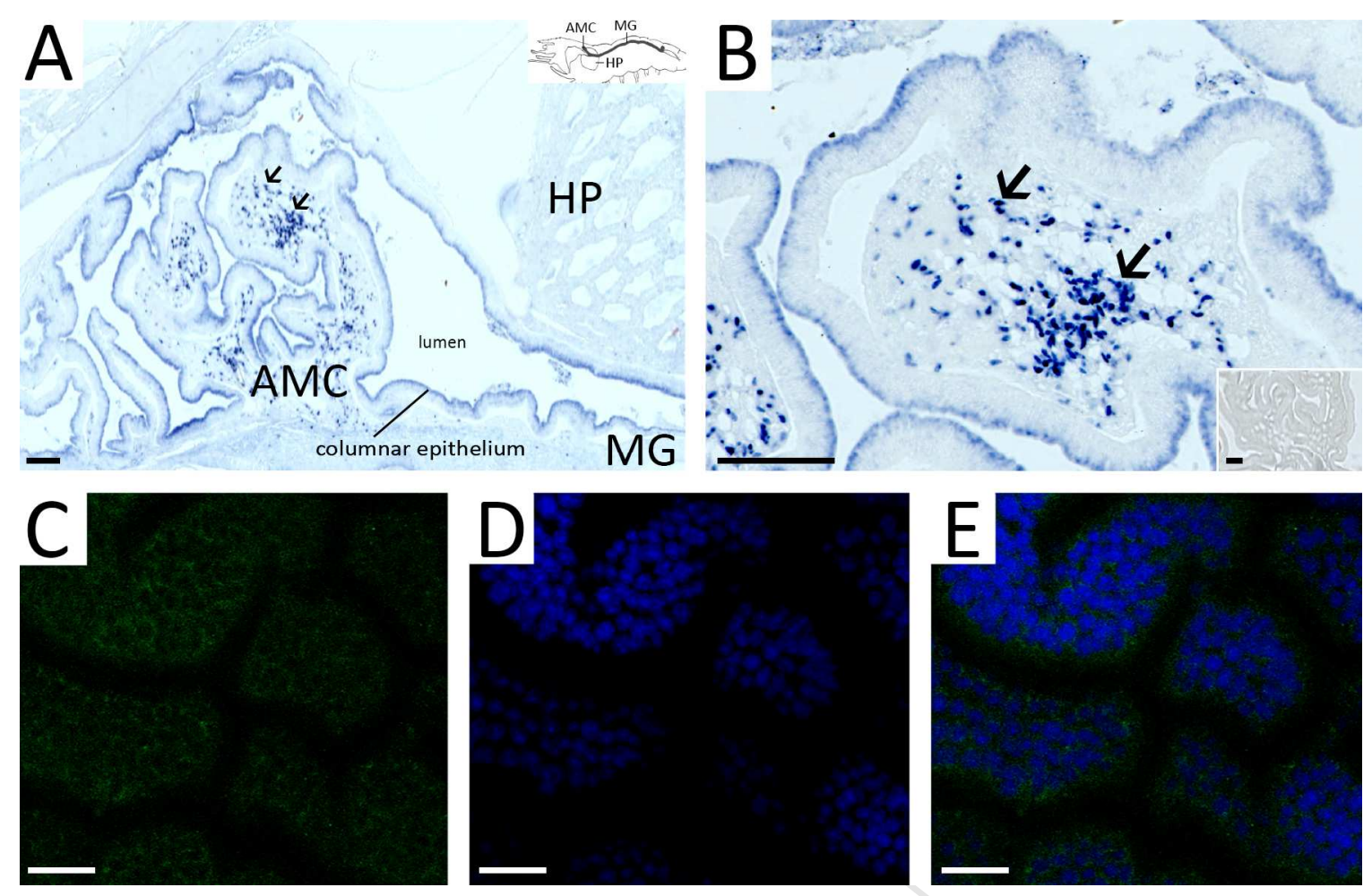



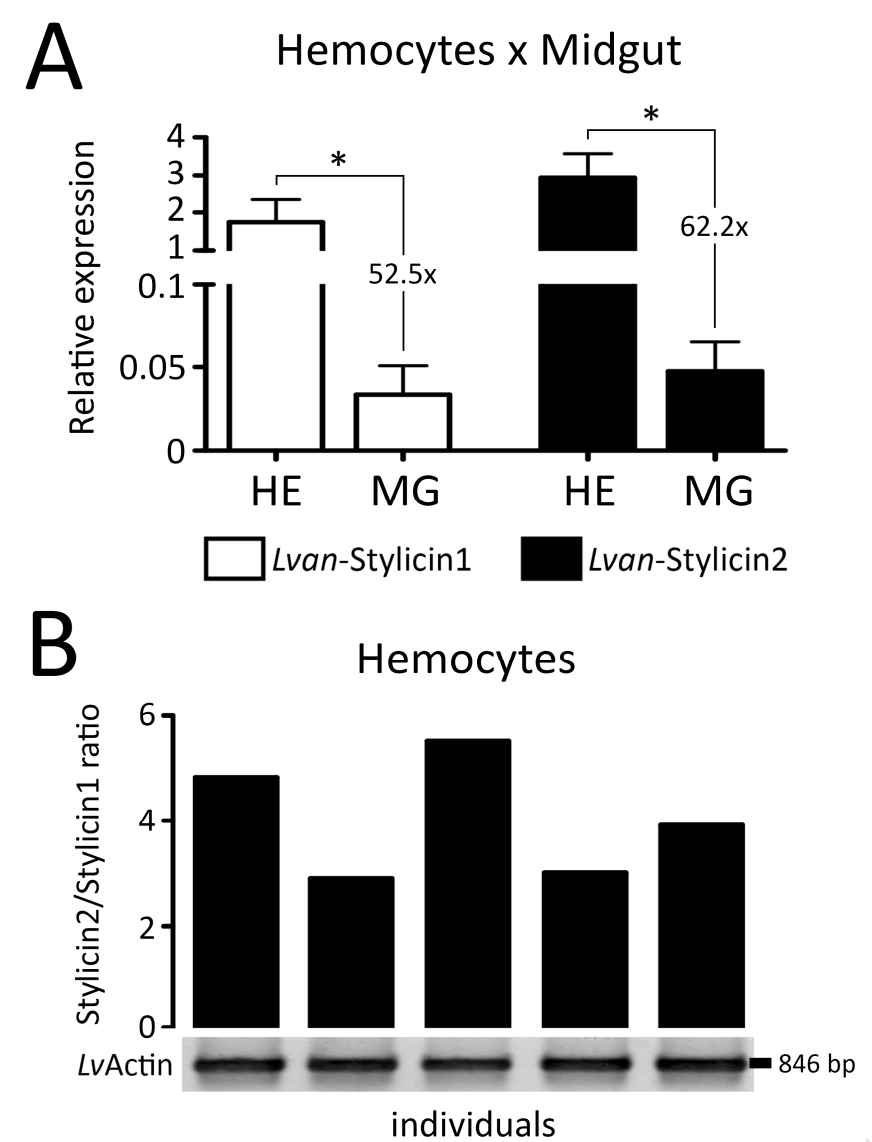


\section{Vibrio harveyi}
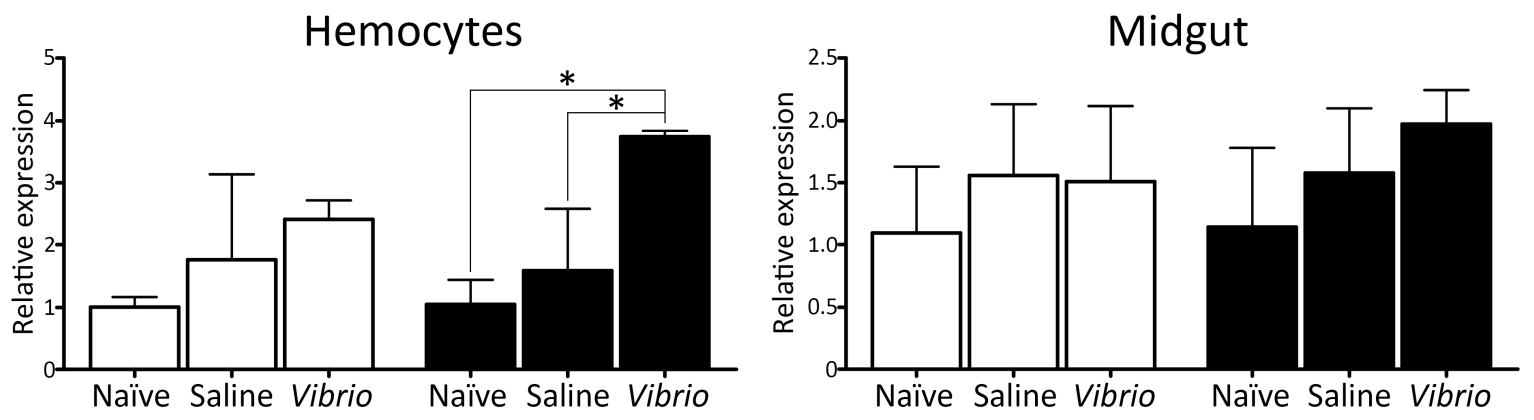

White spot syndrome virus
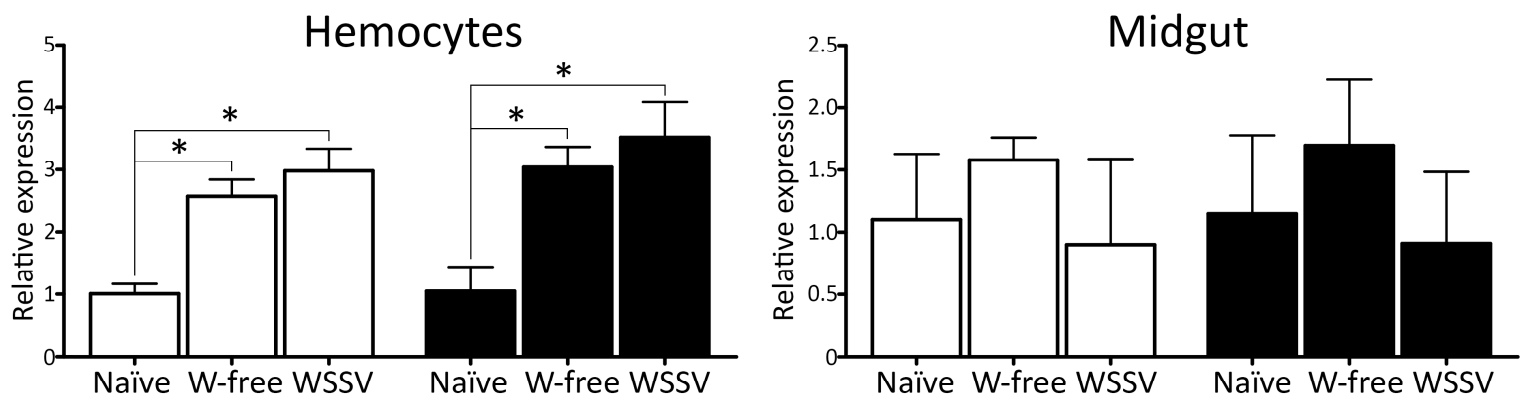

$\square$ Lvan-Stylicin1

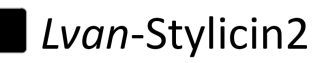



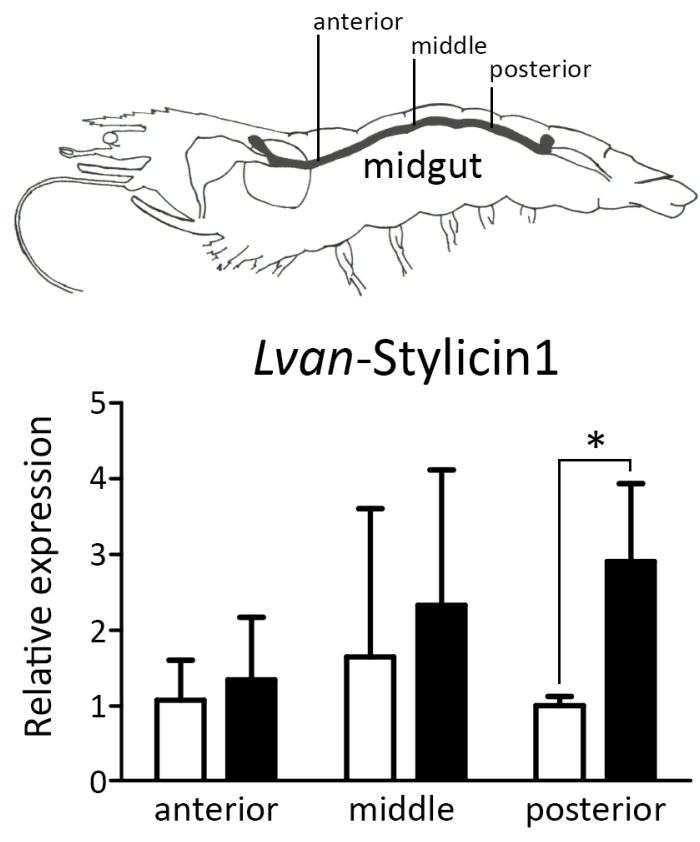

Lvan-Stylicin2

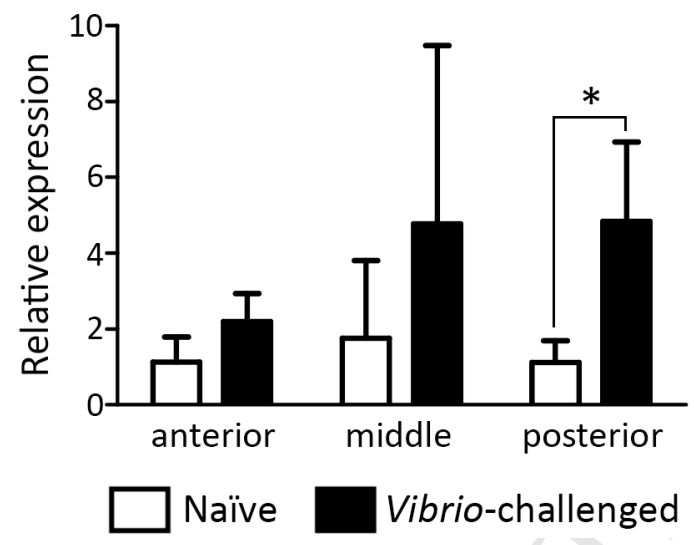


Lvan-Stylicin1

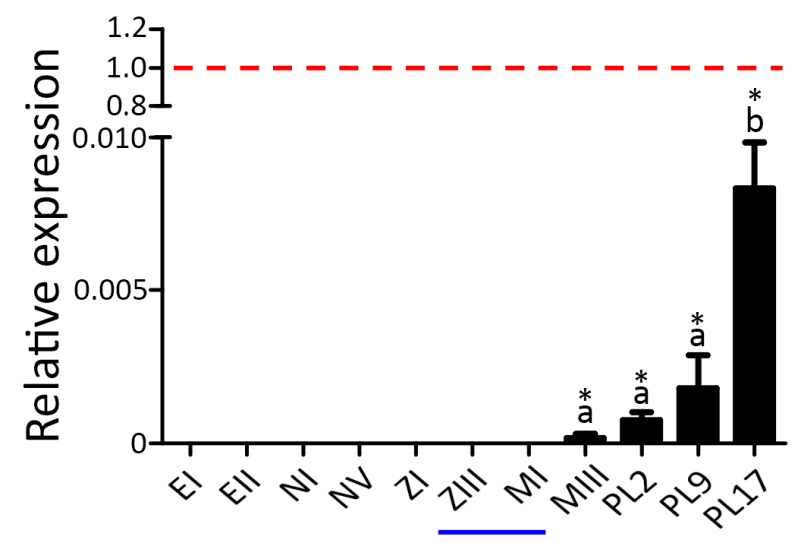

Lvan-Stylicin2

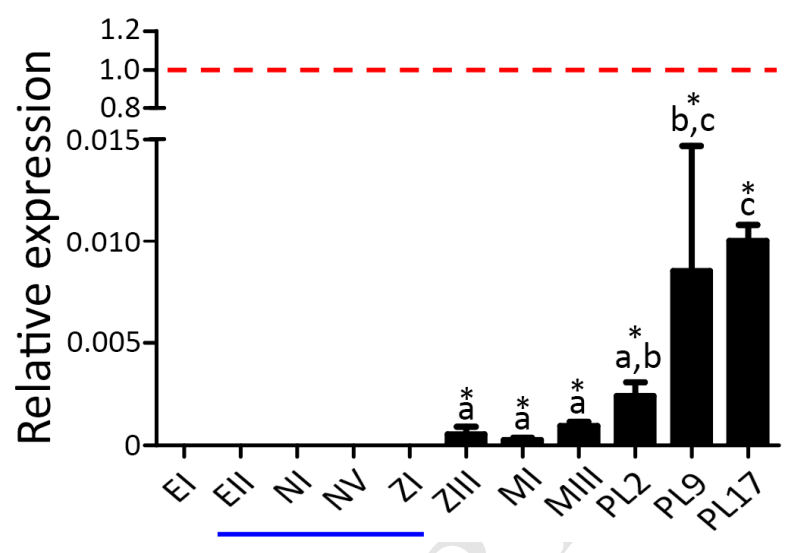

